\title{
At queere tanken Deleuze og de kommende køn
}

Kan en andring $i$ vores maide at tonke på andre vores opfattelse af kon og seksualitet? Ev det $i$ det hele taget muligt at tenke hinsides diskurser og representationer? Denne artikel vil forsøge netop det via filosoffen Gilles Deleuze.

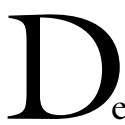

enne artikel vil præsentere den franske filosof Gilles Deleuze (1925-1995) og hans forståelse af tanken som skabelse. Jeg vil undersøge, om tanken kan danne bevæggrund for en artikulation af køn og seksualitet som tilblivelser frem for konstruktioner eller performativer. Artiklen er inddelt i tre dele: En redegørelse for Deleuzes forståelse af tanken og de begreber, der knytter sig hertil i diskussion med Judith Butler (1956-), en genskabelse af queer som filosofisk begreb samt en analyse af det københavnske queer-artspace Warehouse9 i overensstemmelse med artiklens forudgående diskussion. Den gennemgående tese vil være, at kroppen og oplevelsen ikke skal underlægges teorien, men at tanken og kroppen skal blive til med livet som skabelse og bevægelse.

Butlers teori om køn og performativitet er en refleksion over, hvordan subjektet(s $\mathrm{k} ø n)$ konstrueres i lighed med iterative og symbolske diskurser. Hendes teori om kønnets performative materialisering på krop- 
pens overflade (Butler 2007: 185) insisterer på den ene side på konkrete politiske værktøjer til bestridelsen af en normativ praksis. På den anden side, mener jeg, at Butlers teori funderes $i$ en a priori afhængighed af repræsentationen, identiteten og genkendeligheden. Således kan der ikke tilstrækkeligt redegøres for livets kompleksiteter og potentialer, da disse altid allerede er indfanget i og bestemt af sproglige og diskursive konstellationer.

Butlers performativitetsteori er udelukkende en kritisk strategi, da den knyttes til theoria som den model, hvorigennem de forskellige genstandsfelter analyseres og fortolkes. Theoria, oversat fra græsk, betyder 'kontemplation' eller 'et kiggende på' og indikerer en verdensforståelse, hvor bevidstheden er 'uden for' det materiale, der spekuleres over. Teorien antager aprioriske representative billeder eller figurer, hvorigennem tanken og verden udledes og fastsættes. Performativitetsteoriens refleksioner bekræfter repræsentationen som uomgængelig. Subjektet bliver en repræsentation af den iterative og symbolske orden og indgår i en lukket forhandling med repræsentationen, hvor det mulige allerede er forudbestemt. Den teoretiske refleksion bliver det distancerede blik, der bestemmer forholdene inden for denne cirkulation. Queer som dekonstruktiv fremtrædelsesform forbliver bundet til de strukturer, der konstituerer subjektet, hvorfor mulighederne er betinget af det repræsentative plan.

Butlers teori formår altså ikke at gå hinsides subjektpositionen, da hendes teori fastholder genkendelighed som afgørende for de konstituerende og subversive performative betingelser: Man kan kun agere mod normen $i$ en samtidig bekræftelse af normen, fordi man kun er forskellig fra normen. Det er en negativ forskel, hvor noget kun er forskelligt fra noget andet. Subjektets krop, som materialiseres inden for diskurserne (Butler 1993: 4-6), bliver det medium, hvor kønnet forhandles. Kroppen har ingen ontologi, bortset fra de symbolske handlinger, der konstituerer dens virkelighed (Butler 2007: 185), men fremstår alligevel som kønslig a priori. De dekonstruktive muligheder er altså betinget af subjektet som genkendelig agens i relation til og afhængig af den heteronormative matrice samt de strukturer, der betinger subjektet og dets krop. Når kroppen forbliver en forhandling mellem performative praksisser, forbliver den en repræsentation, hvis muligheder er begrænset af common sense: Kroppen måles ud fra analogi, identitet og genkendelighed inden for allerede fastlagte størrelser.

\section{FEMINISMEN OG}

\section{DEN POSITIVE FORSKEL}

Butlers queerteoretiske undersøgelsesformat beror på theoria og common sense. Common sense henviser, ifølge Deleuze, til den fælles formodning om, hvad det intuitivt vil sige at tænke. Vi tror med andre ord, at vi allerede ved, hvad det er at tænke. Dette billede af tanken kalder Deleuze tankens dogmatiske billede:

Det er $i$ dette billede, at alle ved og formodes at vide, hvad det vil sige at tænke. (...) [D]ette billede som allerede på forhånd dømmer alting (...). Vi kan kalde dette billede af tanken et dogmatisk eller ortodokst billede, et moralsk billede (Deleuze 2011: 172; min oversættelse).

Tanken er underordnet en apriorisk, repræsentativ tankefigur og vedbliver at være underlagt det enkelte billede af tanken, der favner teori og filosofi som et hele (ibid.: 172-73).

Tanken som skabelse frem for representation er en befrielse af tanken fra det dogmatiske billede. I kønsfilosofisk regi vil det betyde, at køn og seksualitet kan tænkes anderledes end de diskursive og aprioriske figurer, vi opererer med under tankens dogmatiske billede. At tænke hinsides diskursive modeller og kulturelt-funderede 
tankefigurer kræver, i enighed med engelske Claire Colebrook, en bestridelse af, hvad det vil sige at tænke og gøre teori i traditionel forstand (Colebrook 2008: 22). Først når tanken befries, det vil sige tanken er uden billede, kan vi tænke de immanente potentialer, tilblivelser og mangfoldigheder. At tænke køn og seksualitet som tilblivelser involveret i livet og kroppens heterogene bevægelser og formationer, foranlediger derfor en kobling mellem Deleuzes filosofi og queer. ${ }^{l}$

Netop denne kobling mellem Deleuze og kønsproblematikker, har inspireret flere feministiske tænkere (jf. note 1). Koblingen muliggør nye diskussioner af køn og seksualitet i et felt, der ofte har været dikteret af psykoanalytiske forestillinger. Den feministiske tænkning finder hos Deleuze muligheden i at tænke kvinden som en positiv term, der indebærer et potentiale frem for at være defineret via negation, som hos Butler, eller som mangel. Deleuzes åbne filosofiske projekt tillader, at forestillingen om kvinden ikke allerede er bestemt af kulturelle strukturer eller biologiske skæbner. Fokus på de præ-subjektive og non-repræsentative kræfter, begrebslig kreativitet samt feminismens transformative genbesiddelse af viden muliggør således alternative figurationer og tilblivende-subjekter (Braidotti 2001: 171) hinsides repræsentative billeder. Kvindekønnet affirmeres som et potentiale til at bevæge og tænke hinsides fallocentriske diskurser; forskellen bliver positiv, fordi kvinden ikke længere er i relation til manden, men berettiget i sig selv og skabende i sig selv. Tankens aktivitet befries fra en fallocentrisk dogmatisme (Braidotti 1994: 8).

\section{TANKENS FORSKEL}

I forlængelse af feminismens fokus på køn som positivt potentiale, vil denne artikels kobling af Deleuze og queer analysere, hvad Deleuze kalder forskellen-i-sig-selv [ la différence en elle-même] (Deleuze 2011).
Forskellen er en kraft eller et potentiale, der i enhver produktion eller skabelse udtrykker væren forskelligt; ikke som forskel fra noget andet, men som værende berettiget eller unik i sig selv. Væren udtrykkes på samme måde (som forskellen i sig selv) i alle dens modaliteter (Deleuze 2011: 53; Foucault 2001: 104).

Forskellens kraft er også gentagelsens, da gentagelsen ikke er en statisk replica, men snarere en forskudt forskel. Gentagelsen er den evige gentagelse eller genkomst af forskellen således, at det som gentages er en nyskabelse, der bekræfter forskellens kraft. Gentagelsen er den transgression, hvormed det singulære kommer til udtryk som værende berettiget i sig selv. Forskel og gentagelse tillader en værensfilosofi og tanke, hvor representationen ikke dominerer over forskellen, men hvor væren udtrykkes på en og samme måde, hvilket paradoksalt nok betyder, at væren ikke på forhånd er bestemt af repræsentationen. Væren udtrykker sig på samme måde, fordi forskellen ikke er bestemt af common sense. Væren er altså det, der udtrykker sig som forskel (ibid.: 109), og væren er gentagelsen af forskellen. Forskel og gentagelse kan tænkes som den tilblivelse eller proces, der bekræfter potentialet til altid at skabe det nye.

Det betyder, at denne artikels kobling af Deleuze og queer ikke afviser queerteorien, da det er at falde tilbage $\mathrm{i}$ en negativ forskel, i common sense. Det at koble Deleuze og queer berettiger snarere en ny skabelse, der ikke viser tilbage til en forudgående model, men står som en ligeværdig skabelse.

\section{TANKEN SOM SKABELSE}

At skabe indebærer først og fremmest at frigøre tanken fra det dogmatiske tankebillede. Tanken er ikke den personlige kapacitets spontane udgydelse (Badiou 2000: 11), men en venden sig mod kaos, mod alle de endnu-ikke-aktualiserede potentialer hinsides og latent i enhver formation, subjekt 
løsningerne. Et problem i dette regi er altså ikke det virtuelle potentiale, der fordrer tankens aktivitet og skabelse, men en 'ready-made'. Det dogmatiske tankebillede dømmer på forbaind det, som er det mest værdifulde i tanken, nemlig den tenkende handlings genese samt meningsskabelsen (Deleuze 2011: 206).

Et filosofisk begreb hos Deleuze viser i stedet tilbage til et problem, der kun kan forstås efterhånden som løsningen viser sig; problemet er virtuelt til stede i løsningens tilblivelse som en insisteren. Et begreb kan siges at henvise til et virtuelt problem, der svarer til, men ikke er lig med $\sin (\mathrm{e})$ aktuelle løsning(er):

Det virtuelle besidder en opgaves virkelighed til at blive udført, som et problem, der skal løses: Det er problemet, som orienterer, betinger og fremkalder løsninger, men disse ligner ikke selv problemets betingelse (Deleuze 2011: 274; min oversættelse).

Problemerne forandrer sig og kalder på nye begrebsdannelser.

Den teoretiske refleksion, der vil udtænke løsningen på det allerede givne problem, 'erstattes' af den skabende praksis eller tænkning. Som begreb skal queer ikke forstås som en term, der knytter sig til et særligt kønspolitisk område; queer er ikke en tilegnelse, der modsvarer og allerede udgør de subversive muligheder. Genaktualiserer vi queer som filosofisk begreb, udtrækkes begivenhederne fra de aktuelle tingstilstande og tanken aktiveres, fordi de endnu-ikke-aktualiserede potentialer fremdrages. Skabelsen eller genaktualiseringen af queer imødegår ideen om at aktivere væren de steder, hvor common sense regerer.

Queer kan eksempelvis genaktualiseres som 'at queere'. Queere henviser til en proces uden prædikater eller subjekter, det vil sige uden tilegnelse eller fast udsigelsesposition. At queere bliver en måde, hvorpå tanken gøres aktiv: Begrebets virtuelle potentiale genaktualiseres, fordi tanken skaber be- grebet 'forfra', gentager begrebet via forskellen og fravrister dermed begrebet dets traditionelle betydning (Deleuze 1969: 255). At queere indikerer i-sig-selv en begrebsliggørelse, ikke af et givet problemfelt, men som uophorligt at tenke problematiserende. Et problem og en løsning er ikke allerede forenet, men berettiger hinandens konstante tilblivelse. Genaktualiseringen af queer er dobbelt, da den indebærer både begrebets aktualitet og virtualitet. Med andre ord: Begrebets mangfoldighed genaktualiseres af hele det virtuelle potentiale, det allerede bærer med sig.

At queere er at åbne tanken via begrebets egen konstruktion og udtryk: Den tænkende og problematiserende proces, der aktiverer de felter, der opererer inden for common sense via en aktiverende praksis, der betegner 'at gøre' frem for 'at vare' (Heinskou 2010: 96). At queere søger nedefra eller immanent at aktivere de virtuelle potentialer i en given kontekst, så disse aktualiseres og skaber nye tilblivende kontekster og nye usete mangfoldigheder. At queere tilkendegiver forskellens og gentagelsens positive kraft; forskel og gentagelse som fremtidens elementer, hvor tanken og skabelsen altid forskelliggør sig som et overskud. Tilblivelsen overskrider den repræsentative agens' handlemuligheder i en bestemt nutid samt den negative forskel, der knytter sig hertil til fordel for det virtuelle og forskellen, der peger mod fremtiden (Busk 2001: 154).

At queere er at aktivere tanken. Via begrebets dannelse kan man engagere sig i de variationer og singulariteter, der bekræfter og understøttes af den forskel og gentagelse, som åbner for en ikke-forudbestemt fremtid. Køn og seksualitet i performativitetsteoretisk regi artikuleres af en diskursiv struktur, hvorfor dekonstruktive muligheder bestemmes inden for en repræsentativ ramme. At queere dette felt er også at aktualisere og tilkendegive den transcendentalt empiriske tilgang: Åbne for tilblivelsen og aktivere tænkningen i tanken via en løsrivel- 
se fra den betragtede genstand i et engagement i det empiriske, der er udfoldet af tilblivelsen. I Deleuzes empirisme bliver væren til som begivenhed, som en visen sig af livets kraft og er ikke en subjektiv empirisme (Deleuze 1995: 67-8). Fokus er på de præindividuelle singulariteter og begivenheder. Jeg vil således i en undersøgelse af køn og seksualitet som virtuelle potentialer, tilblivelser og ikke-personlige individuationer queere Warehouse 9 med henblik på at fremdrage forskellens kræfter, der aktualiseres direkte i konkrete og singulære møder mellem mennesker og sanselige og xstetiske tegn.

\section{RUM, SENSIBILITET OG VIRTUELLEE KØN}

Warehouse9 er et tværæstetisk rum, der opererer inden for mange forskellige genrer. Stedet fokuserer primært på køn og seksualitet i politiske, sociale og rstetiske udtryk. Det er min tese, at Warehouse9 er et 'glat rum' [ l'espace lisse], hvor tanken og kroppen kan engagere sig aktivt, og hvor køn og seksualitet bliver aktualiseringer af virtuelle køn, der peger på kroppens rhizomatiske produktion i samspil med verden. Et rhizom er et ikke-hierarkisk netværk uden start eller slut, der altid evner at producere, skabe relationer og knopskyde i usete formationer (Deleuze \& Guattari 2005: 5-35); rhizomet er aktualiseringens bevægelse.

Warehouse9 byder på dukketeater, burlesque-festivaler, performancedebat, digtoplæsninger, T-Lounge (for transkønnede og alt midt i mellem), performances af forskellig art, natklub, galleri etc. Det betyder også, at Warehouse9 som rum hele tiden må igangsætte konkrete fysiske forandringer; rummet kan og må ændre sig fra arrangement til arrangement i den forstand, at nye scener og plateauer bygges, vægge ændrer farve etc. Netop den rhizomatik, hvor det enkelte mister fodfæste til fordel for tværæstetiske mangfoldige udtryk, indebæ- rer, at rummet så at sige aldrig er givet på forhånd. Det indebærer også, at i samspil med rummet, udgør det kropslige og det rstetiske en overskridelse af den kausallogik, der bebuder skellet mellem tid og rum, da rummet, det materielle og xstetiske åbner for en tilblivelse, der artikulerer det potentielt fremtidige. Det vil sige nye kulisser og forskellige brug af scenen og publikumspladser, lyssætning og sceneskift danner en praksis, som hele tiden udvikler og bygger videre på den scene og scenebrug, som var før. Sammenfletningen af tid og rum muliggør frembringelsen af: “multiple virkeligheder" (Heinskou 2010: 117), hvilket understøtter forestillingen om den positive forskel i samspil med altid varierende aktualiseringer formaliseret af det materielle og spatio-temporale.

Ifølge Deleuze og den franske filosof og radikale psykoanalytiker Félix Guattari (1930-1992) er det glatte rum:

(...) en mangfoldighed, som ændrer beskaffenhed når den deler sig (...). Det glatte rum (...) er selv en mangfoldighed af den type, ikke-metrisk, ikke-centreret, retningsmæssigt osv. (Deleuze \& Guattari 2005: 630).

Det glatte rum er altså karakteriseret ved to ting: Det er forskellens rum og rhizomets rum. De forskellige æstetiske udtryk koblet med en mangfoldighed af individer, der udgør et bredt spektrum af varierende køn og seksualiteter, muliggør det direkte møde, der kan tvinge tanken hinsides normer og identiteter til det virtuelle. Rummet opsluges i uophørligt afvigende forskelle:

Hvor hvert objekt, hver ting (...) ser sin identitet slugt af forskellen, hver værende ikke andet end en forskel mellem forskelle (Deleuze 2011: 79; min oversættelse).

Fordi Warehouse9 producerer forskellige xstetiske og politiske udtryk af køn og seksualitet koblet med varierende udtryksformer, kan hver 'aften' ses som aktualiserin- 
ger, hvor køn, seksualitet og xstetik bliver til på forskellig vis. Ikke $\mathrm{i}$ forhold til en norm eller udefrakommende identiteter, der vil operere som repræsentationens center. Hver aften skabes det Deleuze og Guattari kalder "gruppe-subjekter" [un groupe-sujet] (Deleuze \& Guattari 2008: 382-83), som er den kollektive individuation, der holder sig åben mod væren og det virtuelle og tilbyder skiftende roller for dets medlemmer aktualiseret direkte i det glatte rum. Eksempler fra Warehouse9 er TLounge, hvor transkønnede med mere indgår i et kønsligt rhizomatisk kollektiv, der altid er forskelligt-i-sig. Eller danske Miss Fish, som blander dyr, køn og performance i nye formationer og rstetiske udtryk i samspil med rummet. Belgiske Niko Raes, der i sine kropsperformances lader kroppen blive udtryk for rene sanselige og kropslige erfaringer; kroppen tvinges til bevægelser via ophængninger, der bliver til brister i den kausallogiske forståelse af bevægelse. Burlesque-festivalen, der med fire forskellige tilgange til burlesque-genren står som fire entydige aktualiseringer af et virtuelt potentiale.

Det materielle (kroppene, tilskuere, aktører, rummet) og det xstetiske (performances, lys, lyd etc.) skaber varierende udtryk eller sanselige tegn, der bliver til $i$ og med et projekts proces. Netop fordi der $i k$ $k e$ er en klarlagt identitetslogik, men utallige forskellige kønslige udtryk i rummet sammen med altid varierende performances, nærmer Warehouse9 sig det rum, hvor sanseligheden og kønnet frarives et subjekts særstatus. Rummet består snarere af det, Deleuze kalder percepter og affekter:

Percepter er ikke perceptioner, men små pakker af sanseindtryk og relationer, som lever et selvstændigt liv uafhængig af den som føler dem. Affekter er ikke følelser, men derimod tilblivelser, der flyder ud over den, der gennemlever dem (der bliver en anden) (Deleuze 2006b: 167).
Warehouse9 åbner op for den sanselige væren, der nødvendigvis må eksistere uden for et subjekts eller en krops aktualitet. Percepter og affekter er værensformer med gyldighed i sig selv (Deleuze \& Guattari 1996: 208) og er for så vidt tegn adskilt fra selve den handling, hvor de er oplevet eller tænkte. Engagementet i Warehouse9 som glat rum er et direkte møde med sanselige tegn, der: “(...) henviser til måder at leve på $(\ldots)$, de [tegnene] er symptomer på et liv, der bruser frem" (Deleuze 2006b: 174).

Tanken uden billede kan dykke ned i den sanselige væren hinsides aktuelle former. Hermed opløses disse former til fordel for den sanselige væren konstitueret som tilblivelse og virtualitet. Det betyder, at netop via den sanselige væren, bestemt som forskel og virtualitet, percepter og affekter, kan tanken fremdrage i Warehouse9 virtuelle køn og seksualiteter, netop fordi disse aktualiseres i mødet med tegnet og rummet som mangfoldighed og forskel. Warehouse9 er et rum altid-forskelligt-i-sig-selv; en multipel virkelighed afledt af det virtuelles enhed, forskellen-i-sig-selv. Det sensible bliver, hvad danske Carsten Madsen kalder "kræfternes formløse æstetik" (Madsen 2001: 263), der åbner for tankens og værens frihed.

I stedet for fastlagte kønslige størrelser og seksuelle mønstre, er køn og seksualitet virtuelle potentialer, der kan synliggøres og aktualiseres i en rhizomatisk knopskydning af xstetiske og kropslige tegn. Denne knopskydning vil altid hente sin styrke i forskellen og gentagelsen: Evnen til om og om igen at være åben for livet og tilblivelsen, åben for det virtuelle og lade livet bruse frem. Den aktuelle identitet undermineres til fordel for de mikroseksuelle og -kønslige variationers aktiviteter, som allerede handler i et nu og spænder over en umiddelbar fortid-fremtid (Parisi 2009: 88). Man skal således tænke den uformelle materies variation, krxfternes intensive modulation og formernes agitation, der er det virtuelles 
privilegium (Sauvagnargues 2004: 149). Des mere køn og seksualitet tænkes i forhold til en større rhizomatisk produktion, des mere er seksualitet og køn afholdt fra at blive sublimeret til genkendelige eller ideologiske størrelser (Deleuze \& Parnet 2006: 75). Køn og seksualitet fremdrages via tænkningen som virtuelle køn uden subjekt. Det kollektive og mangfoldige træder i stedet for det partikulære. Køn og seksualitet involveres i et tværæstetisk netværk af skabende relationer mellem sammensatte sansninger og udtryk, der åbnes af tanken uden billede. Det æstetiske udtryk bliver altså en særlig måde, hvorpå tanken kan give konsistens til virtuelle køn i samspil med xstetiske udtryk, hvor altid-forskellige kollektive ytringer knopskyder.

\section{DeT KOMMENDE}

Den tanke, der åbner væren, bekræfter samtidigt livet som en strøm af immanente begivenheder og singulariteter, hvorfra ethvert subjekt eller objekt er fremkaldt, og gør dette hinsides aktuelle konstellationer således, at verden bekræftes som tilblivelse. At queere tanken og common sense åbner for livet som en dynamisk strøm og potentiale, som ren immanens og fuldstændig kraft (Deleuze 1995: 68) og for tanken som praksis og proces. Produktionen og tilblivelsen har ikke på forhånd et forudbestemt mål i sigte. Det er det kommende folk (Deleuze \& Guattari 1996: 141), den kommende tanke eller de kommende køn. Common sense omvendes til fordel for de virtuelle potentialer, affekter og percepter, sanseligheder og singulariteter. Tanken som skabelse er den frisættende bevægelse, hvor væren og livet affirmeres; hvor potentialet til altid at skabe det nye, til altid at tænke og leve det utænkte og ulevede uafhængigt af representationens domæne affirmeres og imødegås. Med Deleuzes mangfoldige og varierende filosofi i baghånden kan vi engagere os i tanken som skabelse og livet som tilblivelse og aktivere og aktualisere de vir- tuelle køn og seksualiteter. Det er et frisættende, fremtidigt projekt, hvor det endnu er uvist, hvad kroppen kan, og hvad tankens frisættende rum kan tilbyde os.

\section{Noter}

1. Det er ikke første gang kønsfilosofi og Deleuze kobles. Blandt mere fremtrædende navne er italiensk-australske Rosi Braidotti (bosat og arbejdende i Nederlandene), der med sit begreb om 'det nomadiske subjekt' har forsøgt at skabe en feministisk filosofi, som plæderer for en kobling mellem Deleuzes begreb om nomadisme og den franske feministiske filosof og psykoanalytiker Luce Irigarays tanke om kønsforskellens primat (Braidotti 1994). Hun har desuden udviklet Deleuzes filosofi i et etisk projekt og været med til at skabe fundamentet til New Materialism (Braidotti 2002, 2006). Australske Elizabeth Grosz har tænkt Deleuze i relation til både feministiske og queerfilosofiske problemstillinger ud fra et kropsfænomenologisk og tidspolitisk perspektiv, der også henter inspiration hos den franske filosof Henri Bergson (Grosz 1994, 2001, 2005); en inspiration der også lægger til grund for den amerikanske professor Dorothea Olkowskis analyse af Deleuze og feminisme (Olkowski 1999). Den allerede nævnte Colebrook har diskuteret Deleuze i et feministisk perspektiv (Colebrook 2001) samt i en queerfilosofisk optik (Colebrook 2008, 2009), som også er tilfældet i canadiske David V. Ruffolos forståelse af det 'post-queer' (Ruffolo 2009). I Danmark har Marie Bruvik Heinskou i sin ph.d. En kompleks affare-anmeldte voldtegter i Danmark (Heinskou 2010) blandt andet gjort brug af Deleuze i en empirisk undersøgelse af væren udgjort af non-lineære begivenheder for blandt andet bedre at kunne klargøre for: “(...) seksualitet og senmodernitet som værende forbundet $i$ et netværk af forskellige og forandrende betingelser" (Heinskou 2010: 117). Dermed kan Heinskou analysere særlige rummelige erfaringer som værende immanente og tilblivende i et særligt socialt erfaringsfelt (ibid.: 117). Edinburgh University Press har udgivet Deleuze \& Feminist Theory (2000) og Deleuze \& Queer Theory (2009).

2 . Kontemplation er et vigtigt begreb hos Deleuze, der dog har en anden betydning end den, som knytter sig til theoria fremlagt her i artiklen. Af pladsmæssige årsager kan denne begrebsafklaring ikke foretages her (se evt. Deleuze \& Guattari 1996: 226; Deleuze 2011). 


\section{LITTERATUR}

- Badiou, Alain (2000): Deleuze. The Clamor of Being. University of Minnesota Press, Minneapolis \& London.

- Braidotti, Rosi (1994):Nomadic Subjects. Columbia University Press, New York.

- Braidotti, Rosi (2001): Teratologies, in: Ian

Buchanan \& Claire Colebrook (eds.): Deleuze and Feminist Theory. Edinburgh University Press, Edinburgh.

- Braidotti, Rosi (2002): Metamorphosis. Polity

Press, Cambridge.

- Braidotti, Rosi (2006): Transpositions. Polity

Press, Cambridge.

- Busk, Malene (2001): Tankens Passion. Om subjektivitetsproblematikker i Gilles Deleuzes filosofi, i: Mischa Sloth Carlsen, Karsten Gam Nielsen \& Kim Su Rasmussen (eds.): Flugtlinier. Om Deleuzes filosofi. Museum Tusculanums Forlag, Københavns Universitet, København.

- Butler, Judith (1993): Bodies that Matter. Routledge, New York \& London.

- Butler, Judith (2007): Gender Trouble. Routledge, New York \& London.

- Colebrook, Claire (2001): Is Sexual Difference a Problem?, in: Ian Buchanan \& Claire Colebrook (eds.): Deleuze and Feminist Theory. Edinburgh University Press, Edinburgh.

- Colebrook, Claire (2008): How Queer Can You Go? Theory, Normality and Normativity, in Noreen Giffney \& Myra J. Hird (eds.): Queering the Non/Human. Ashgate, Hampshire \& Burlington. - Colebrook, Claire (2009): On the Very Possibility of Queer Theory, in: Chrysanthi Nigianni og Merl Storr (eds.): Deleuze and Queer Theory.

Edinburgh University Press, Edinburgh.

- Deleuze, Gilles (1969): Logique du Sens. Les Éditions de Minuit, Paris.

- Deleuze, Gilles (1995): Immanensen: et liv ..., i:

Kritik 1995/118

- Deleuze, Gilles (2006a): Nietzsche and Philosophy. Continuum, London \& New York.

- Deleuze, Gilles (2006b): Forhandlinger. DET lille FORLAG og Samlerens Bogklub, Frederiksberg.

- Deleuze, Gilles (2011): Différence et Répétition.

Presses Universitaires de France, Paris.

- Deleuze, Gilles \& Guattari, Félix (1996): Hvad er filosofi? Gyldendal, København.

- Deleuze, Gilles \& Guattari, Félix (2005): Tusind Plateaner. Kapitalisme og Skizofreni. Det Kongelige Danske Kunstakademis Billedkunstskoler, København.

- Deleuze, Gilles \& Guattari, Félix (2008): AntiOedipus. Capitalism and Schizophrenia. Continuum, London.
- Deleuze, Gilles \& Parnet, Claire (2006): Dialogues II. Continuum, London \& New York. - Foucault, Michel (2001): Theatrum philosophicum, i: Mischa Sloth Carlsen, Karsten Gam Nielsen \& Kim Su Rasmussen (eds.): Flugtlinier. Om Deleuzes filosofi. Museum Tusculanums Forlag, Københavns Universitet, København.

- Grosz, Elizabeth (1994): Volatile Bodies. Indiana University Press, Bloomington.

- Grosz, Elizabeth (2001): Deleuze's Bergson: Duration, the Virtual and a Politics of the Future, in: Ian Buchanan \& Claire Colebrook (eds.): Deleuze and Feminist Theory. Edinburgh University Press, Edinburgh.

- Grosz, Elizabeth (2005): Time Travels. Feminism, Nature, Power. Duke University Press, Durham \& London.

- Gualandi, Alberto (1998): Le Problème de la Vérité Scientifique dans la Philosophie Française Contemporaine. La Rupture et L'Événement.

L'Harmattan, Paris.

- Heinskou, Marie Bruvik (2010): En kompleks affore - anmeldte voldtegter $i$ Danmark. Ph-d.-afhandling, Sociologisk Institut, Københavns Universitet, København.

- Madsen, Carsten (2001): Kræfternes formløse xstetik. Gilles Deleuzes forståelse af tanke og kunst, i: Mischa Sloth Carlsen, Karsten Gam Nielsen \& Kim Su Rasmussen (eds.): Flugtlinier. Om Deleuzes filosofi. Museum Tusculanums Forlag, Københavns Universitet, København.

- Olkowski, Dorothea (1999): Gilles Deleuze and the Ruin of Representation. University of California Press, California.

- Parisi, Luciana (2009): The Adventures of a Sex, in: Chrysanthi Nigianni og Merl Storr (eds.): Deleuze and Queer Theory. Edinburgh University Press, Edinburgh.

- Ruffolo, David V. (2009): Post-Queer Politics, Ashgate, Surrey.

- Sauvagnargues, Anne (2004): Deleuze. De l'animal à l'art, i François Zourabichvili (ed.): $L a$ Philosophie de Deleuze. Presses Universitaires de France, Paris.

\section{SumMary}

Queering Thought

Deleuze and the sexes to come

This article argues that queer theory in relation to Judith Butler is unable to account for the complexities of life's creation and imma- 
nent potential that exist prior to and in between the hierarchical representations of discourses, language and subjects.

This article seeks an opening and understanding of thought as creation, not representation. Through the philosophy of french philosopher Gilles Deleuze (1925-1995) thought is freed from its image and thereby activated in thinking. It is then possible to think and engage in life as becoming; life as consisting of virtual potentials, the alwaysnot-yet-actualised.
The article proceeds by activating queer as a philosophical concept: 'to queer' thus focusing on the 'to do', not the 'to be'; and analysing the queer-art-space Warehouse 9 as a smooth space, where it is possible to encounter virtual sexes in concordance with sensible signs and aesthetic expressions.

Tue Løkkegaard

KA-studerende i Litteraturvidenskab

Københavns Universitet

Redaktør på Kulturo: Tidsskrift for Kunst, Litteratur og Politik. 